OPEN ACCESS

Edited by:

Yuji Morita,

Aichi Gakuin University, Japan

Reviewed by:

Monika Staniszewska,

National Institute of Public

Health-National Institute of Hygiene,

Poland

Pedro Ismael Da Silva Junior

Instituto Butantan, Brazi

ChangZhong Wang,

Anhui University of Chinese Medicine,

China

*Correspondence: Cristina de Andrade Monteiro cristina.monteiro@ceuma.br

Specialty section:

This article was submitted to

Antimicrobials, Resistance and

Chemotherapy,

a section of the journal

Frontiers in Microbiology

Received: 21 September 2016

Accepted: 23 March 2017

Published: 10 April 2017

Citation:

Terças AG, Monteiro AdS, Moffa EB, Santos JRAd, Sousa EMd, Pinto ARB,

Costa PCdS, Borges ACR

Torres $L M B$, Barros Filho $A K D$,

Fernandes ES and Monteiro CdA (2017) Phytochemical Characterization

of Terminalia catappa Linn. Extracts and Their antifungal Activities against Candida spp. Front. Microbiol. 8:595.

doi: 10.3389/fmicb.2017.00595

\section{Phytochemical Characterization of Terminalia catappa Linn. Extracts and Their antifungal Activities against Candida spp.}

\author{
Analucia G. Terças ${ }^{1}$, Andrea de Souza Monteiro ${ }^{2}$, Eduardo B. Moffa ${ }^{3}$, \\ Julliana R. A. dos Santos ${ }^{4}$, Eduardo M. de Sousa ${ }^{2}$, Anna R. B. Pinto ${ }^{4}$, \\ Paola C. da Silva Costa ${ }^{4}$, Antonio C. R. Borges ${ }^{5}$, Luce M. B. Torres ${ }^{6}$, \\ Allan K. D. Barros Filho ${ }^{1}$, Elizabeth S. Fernandes ${ }^{7}$ and Cristina de Andrade Monteiro ${ }^{4 *}$

\begin{abstract}
'Departamento de Engenharia Elétrica, Programa de Doutorado em Biotecnologia da Rede Nordeste de Biotecnologia Universidade Federal do Maranhão, São Luís, Brazil, ${ }^{2}$ Laboratório de Patogênese Bacteriana, Programa de Mestrado em Biologia Parasitária, Universidade Ceuma, São Luís, Brazil, ${ }^{3}$ Laboratório de Micologia Médica, Programa de Mestrado em Odontologia, Universidade Ceuma, São Luís, Brazil, ${ }^{4}$ Laboratório de Micologia Médica, Programa de Mestrado em Biologia Parasitária, Universidade Ceuma, São Luís, Brazil, ${ }^{5}$ Departamento de Ciências Fisiológicas, Programa de Doutorado em Biotecnologia da Rede Nordeste de Biotecnologia, Universidade Federal do Maranhão, São Luís, Brazil, ${ }^{6}$ Instituto de Botânica, Centro de Pesquisa em Ecologia e Fisiologia, São Paulo, Brasil, ${ }^{7}$ Programa de Pós-graduação, Universidade Ceuma, São Luís, Brazil
\end{abstract}

Terminalia catappa Linn bark is used to treat dysentery by various populations in Southeast Asian countries, and its leaves have also been used in traditional medicine to treat hepatitis in India and the Philippines. Here, the antifungal actions of crude hydro-alcoholic extract (TcHE) and fractions from T. catappa leaves were assessed via the agar diffusion and microdilution tests on Candida reference strains and clinical isolates from patients with acquired immunodeficiency syndrome (AIDS). Additionally, the potential cytotoxic effects of TcHE were assessed on cultured human peripheral blood mononuclear cells (PBMC). T. catappa fractions and sub-fractions were analyzed by gas chromatography coupled to mass spectrometry with electron impact (GC/MS/El), high-performance liquid chromatography coupled to mass spectrometry "electrospray" ionization in positive mode (HPLC/MS/MS/ESI ${ }^{+}$) and hydrogen nuclear magnetic resonance $\left({ }^{1} \mathrm{HNMR}\right)$. TcHE and its fractions were able to inhibit the growth of all tested Candida strains with the $n$-butanol $(\mathrm{FBuOH})$ fraction presenting the best antifungal activity. Testing of different FBuOH sub-fractions (SF) showed that SF10 was the most active against Candida spp. Fractioning of SF10 demonstrated that 5 out of its 15 sub-fractions were active against Candida spp., with SF10.5 presenting the highest activity. Chemical analysis of SF10 detected hydrolysable tannins (punicalin, punicalagin), gallic acid and flavonoid C-glycosides. Overall, the results showed that T. catappa L. leaf extract, fractions and sub-fractions were antifungal against Candida spp. and may be useful to treat diseases caused by this fungus.

Keywords: plant extracts, candidiasis, AIDS, antifungical agents, Candida, Terminalia catappa 


\section{INTRODUCTION}

The increase number of individuals infected with human immunodeficiency virus (HIV) has stimulated research regarding Candida spp., which are opportunistic pathogens responsible for one of the most common oral diseases affecting immunosuppressed individuals, the oropharyngeal candidiasis (OPC) (Hamza et al., 2008; Moura et al., 2010; Annapurna et al., 2012). Though Candida albicans is the most frequently isolated species as colonizer and pathogen of the oral mucosa, other Candida species, such as Candida tropicalis, Candida krusei, and Candida glabrata are recovered increasingly, mainly in HIV-infected individuals (Gugnani et al., 2003; Hamza et al., 2008; Patil et al., 2015). Candida yeasts cause oropharyngeal, esophageal, laryngeal, and invasive candidiasis (Patil et al., 2015).

Ten to $49 \%$ of HIV patients die due to invasive fungal infection (Favalessa et al., 2010). In addition, the constant use of antifungal drugs in the past few decades has increased the numbers of infection caused by resistant Candida strains. Thus, special attention has been given to research focused on medicinal plants to identify new molecules with antimicrobial potential (Fyhrquist et al., 2002; Jagessar and Alleyne, 2011; Packer et al., 2015).

Plants and their derived compounds have been used worldwide for the prevention and treatment of diseases (Triantafillidis et al., 2016). Terminalia catappa Linn. plant has been investigated in various pharmaceutical studies as it contains a variety of chemical components (Pandya et al., 2013; Yeh et al., 2014). T. catappa L. leaf extracts exhibit biological activities, including antioxidant (punicalagin, punicalin, terfluvina $\mathrm{A}$ and $\mathrm{B}$, chebulic acid, benzoic acid, cumaric, and its derivatives) (Chen and Li, 2006; Chyau et al., 2006; Kinoshita et al., 2007), antidiabetic ( $\beta$-carotene) (Anand et al., 2015), anticancer (punicalagin) (Naitik et al., 2012), antiviral (ellagic acid) (Tan et al., 1991), anti-inflammatory (triterpenic acids, especially ursolicacid and its derivatives) (Fan et al., 2004), antimicrobial (flavones and flavanols) (Kloucek et al., 2005; Nair and Chanda,

\footnotetext{
Abbreviations: AIDS, Acquired Immunodeficiency Syndrome; ANOVA, Analysis of Variance; ATB, Automation Triple Resonance Broadband; ATCC, American Type Culture Collection; BSTFA+TMCS, N,O-bis (trimethylsilyl) trifluoroacetamide with trimethylchlorosilane; CFU, Colony Forming Units; CLSI, Clinical and Laboratory Standards Institute; DMSO, Dimethyl Sulfoxide; FAcOEt, Ethyl acetate fraction; $\mathrm{FBuOH}, \mathrm{n}$-butanol fraction; FHEX, Hexane fraction; GC/MS/EI, Gas Chromatography coupled to Mass Spectrometry withElectron Impact ionization; HIV, Human Immunodeficiency Virus; ${ }^{1}$ HNMR, Nuclear Magnetic Resonance of Hydrogen; HPLC/UV, Highperformance liquid chromatography coupled with Ultraviolet spectroscopy; HPLC-MS/MS/ES ${ }^{+}$, Liquid Chromatography coupled to Electrospray Ionization Mass Spectrometry in positive mode; MIC, Minimum Inhibitory Concentration; MTT, 3-(4,5-dimethylthiazol-2-yl)-2,5-diphenyl tetrazolium bromide; NIST/EPA/NIH, National Institute of Standard and Technology Mass Spectral Library/Environmental Protection Agency/National institutes of Healthy; OPC, Oropharyngeal Candidiasis; PBMC, Human Peripheral Blood Cell; RPMI, Roswell Park Memorial Institute medium; SD, Standard Deviation; SDA, Sabouraud Dextrose Agar; SF, Sub-fractions; SF10-FbuOH, FBuOH subfraction 10; TcHE, Terminalia catappa Hydroalcoholic Extract; TIC, Total Ion Chromatogram; TMS, Tetramethylsilane; UFMA, Federal University of Maranhão.
}

2008; Shinde et al., 2009), and hepato-protective activities (punicalagin, punicalin) (Kinoshita et al., 2007).

In India, a plaster of T. catappa leaves is used to treat scabies, leprosy wounds and other skin diseases (Nair and Chanda, 2008). Its traditional use includes the treatment of diarrhea and fever, especially in India, the Philippines and Malaysia (Kloucek et al., 2005; Shinde et al., 2009). Previous studies suggest that the most polar fractions obtained from T. catappa leaves are effective against bacteria (Shinde et al., 2009) and fungi (Jagessar and Alleyne, 2011), but little is known of T. catappa effects against Candida spp. Here, we investigated the antifungal properties of the hydroalcoholic extract obtained from T. catappa leaves (TcHE). We also assessed the antifungal actions of fractions and sub-fractions (SF) obtained from TcHE. Additionally, compounds of the most effective SF were identified.

\section{MATERIALS AND METHODS}

\section{Plant Materials and Extraction}

T. catappa Linn (Combretaceae) leaves were collected in São José de Ribamar, Maranhão, and identified by the Attic Herbarium Seabra of the Federal University of Maranhão (São Luís, Brazil) under the voucher specimen $\mathrm{n}^{\circ}$. 01062. The leaves were dried at room temperature for 1 week. The dried material was then triturated in a slicer to obtain a fine powder. Two hundred grams of powder were extracted twice with $600 \mathrm{ml}$ of ethanol (70\%, $\mathrm{v} / \mathrm{v}$ ) at room temperature for 2 days with an $8 \mathrm{~h}$-period between extractions. The mixture was filtered through cellulose filter paper (Whatman No. 1, GE Healthcare UK, Amersham, UK) and concentrated on a rotary evaporator (Büchi Labortechnik AG, Flawil, Switzerland) under reduced pressure at $40^{\circ} \mathrm{C}$.

The crude hydro-alcoholic extract (TcHE) was lyophilized, then $(200 \mathrm{~g})$ resuspended in $600 \mathrm{ml} \mathrm{MeOH} / \mathrm{H}_{2} \mathrm{O}$ (Merck, Darmstadt, Germany) (80:20, v/v). The samples were sequentially subjected to liquid-liquid partition with hexane (Merck, Darmstadt, Germany), followed by ethyl acetate (Merck, Darmstadt, Germany), then $n$-butanol (Merck, Darmstadt, Germany), resulting in three fractions with different polarities: the hexane fraction (FHEX), which was the least polar fraction; the ethyl acetate fraction (FAcOEt) with intermediate polarity; and the $n$-butanol fraction $(\mathrm{FBuOH})$, the most polar fraction. The resulting fractions were concentrated on a rotary evaporator (Büchi Labortechnik AG, Flawil, Switzerland), lyophilized (VirTis Lyophilizer Tray Dryer, New York, United States), weighed and stored in sterile glass containers at $-20^{\circ} \mathrm{C}$.

\section{Isolation and Identification of Candida Strains}

Candida spp. samples were obtained from the buccal mucosa of 52 patients with acquired immunodeficiency syndrome (AIDS) attending the Hospital Presidente Vargas in São Luis, Brazil, after a written informed consent was obtained. Individuals (30 male and 22 female) were 19-61 years old. Samples were collected by rubbing sterile swabs on the oral mucosa, and were then inoculated into tubes containing $0.85 \%$ saline (ISOFAR, Paraná, Brazil). Candida spp. were isolated in CHROMagar (Difco, Detroit, MI, USA) and 
incubated at $37^{\circ} \mathrm{C}$ for $48 \mathrm{~h}$. The biochemical identification of the yeast was performed in automated Vitek- $2^{\circledR}$ system (Compact, bioMérieux, Marcy-L 'Etoile, France), according to the manufacturer's recommendations. The study was reviewed and approved by the Ethics Committee of the Federal University of Maranhão (UFMA) under the protocol number 23115-006 540/2009-40.

\section{Monitoring of Antifungal Activity Microdilution Assay}

The antifungal activities of TcHE, FHEX, FAcOEt, and FBuOH were evaluated in 20 clinical isolates (14 Candida albicans, 2 Candida glabrata, 2 Candida tropicalis, and 2 Candida krusei) and three reference strains (C. albicans ATCC 90028, C. glabrata ATCC 2001, and C. krusei ATCC 6258) of Candida spp. based on the proposal of the Clinical and Laboratory Standards Institute (CLSI) M27-A3 (CLSI, 2008). References strains were kindly donated by the São Paulo State University, Araraquara Dental School, São Paulo, Brazil. The antifungal effects of all $\mathrm{FBuOH}$ SFs (primary and secondary) were initially assessed against two clinical isolates of C. albicans (C. albicans 02 and C. albicans 04) and the reference strain C. albicans ATCC 90028 in the agar diffusion method using cavity plates (McGinnis, 1980). The effects of the most active SFs were also evaluated in the microdilution method, against Candida spp. reference strains and four clinical isolates (C. albicans 02, C. glabrata 01, C. tropicalis 01, C. krusei 02), one from each species of Candida.

In order to determine antifungal activities in the microdilution assay, the TcHE and its fractions were diluted in RPMI1640 culture medium (Sigma-Aldrich, St. Louis, MO, USA) at concentrations of $0.18-48 \mathrm{mg} / \mathrm{ml}$ and were incubated in 96-well plates (at $37^{\circ} \mathrm{C}$, for $48 \mathrm{~h}$ ) with Candida spp. $\left(2.5 \times 10^{3} \mathrm{CFU} / \mathrm{ml}\right)$, as recommended by the CLSI M27-A3 protocol (CLSI, 2008). Fluconazole $(0.25-64 \mu \mathrm{g} / \mathrm{ml}$; Pfizer, Brazil) and amphotericin B (0.0625-16 $\mu \mathrm{g} / \mathrm{ml}$; Sigma-Aldrich, St. Louis, MO, USA) were used as positive controls. Vehicle (RPMI)-treated wells were used as negative controls. Following incubation, the absorbance was read at $540 \mathrm{~nm}$ in a microplate reader (BioMérieux Reader 250 Version 2.0.5, Genève, Suisse). All tests were performed in triplicate.

In a separate series of experiments, the most active SFs were tested at concentrations of $0.2-56$ or $0.18-48 \mu \mathrm{g} / \mathrm{ml}$, depending on their initial amount. In all experiments, the absorbance obtained from wells containing either TcHE, fractions or SFs plus medium and inoculum was discounted from those obtained from wells containing extract, fractions or SFs plus medium only. Then, the percentages of Candida spp. growth inhibition were determined for each strain using the formula outlined below:

$$
\% \text { Inhibition }=(\mathrm{Ac}-\mathrm{At}) / \mathrm{Ac} \times 100
$$

Where $\mathrm{Ac}=$ control absorbance and $\mathrm{At}=$ test absorbance. The MIC of each compound was defined as the lowest concentration at which no fungal growth was observed.

\section{Agar Diffusion Assay}

The antifungal effects of $\mathrm{FBuOH}$ SFs were evaluated in the agar diffusion method (Moody et al., 2004). Briefly, $20 \mathrm{ml}$ of
Sabouraud dextrose agar medium (SDA) (Difco Laboratories, Detroit, MI, USA) containing chloramphenicol were added to Petri dishes $(100 \times 200 \mathrm{~mm}$ in diameter $)$ according to the manufacturer's recommendations. After solidification, the plates were incubated for $24 \mathrm{~h}$ at $37^{\circ} \mathrm{C}$ to assess contamination. Then, Candida spp. (100 $\mu$ l of standardized inoculum solution with $10^{3} \mathrm{CFU} / \mathrm{ml}$ ) was seeded on the plates with sterile swabs. Fifty-microliter extract volumes at different concentrations were added into perforations of approximately $5 \mathrm{~mm}$ in diameter in solid culture medium. Fluconazole $(64 \mu \mathrm{g} / \mathrm{ml})$ (Pfizer, SP, Brazil) and saline $(0.9 \%)$ were used as positive and negative controls, respectively. All tests were performed in triplicate. The inhibition zones were measured in millimeters, and the data were analyzed by performing statistical tests.

\section{Human Peripheral Blood Cell (PBMC) Viability}

PBMCs were collected from 20 healthy human volunteers (non-smoking donors who had not received any medication for the last 15 days prior to sampling, aged 18-35 years old) who provided written formal consent. This study was approved by the Ethics Committee in Research of Ceuma University (protocol number: 105/2014). Cells were obtained by the standard method of density-gradient centrifugation over Histopaque ${ }^{\circledR}-1119$ according to the manufacturer's instructions. PBMCs were then suspended in a supplemented DMEM culture medium (Life Technologies, Brazil) containing 10\% fetal bovine serum (Life Technologies, Brazil), streptomycin $(100 \mu \mathrm{g} / \mathrm{ml}$; Sigma-Aldrich, Brazil) and penicillin $(100 \mathrm{U} / \mathrm{ml}$; Sigma-Aldrich, Brazil). PBMCs were plated in 96-well plates (2 $\times 10^{5}$ cells/well in $\left.200 \mu \mathrm{l}\right)$ and incubated with either phosphatebuffered saline (PBS; negative control), or TcHE (0.001-10 $\mathrm{mg} / \mathrm{ml}$ ). Lipopolysaccharide (LPS)-treated wells were used as positive control. Cells were incubated at $37^{\circ} \mathrm{C}$ in a $5 \% \mathrm{CO}_{2}$ atmosphere for $24 \mathrm{~h}$. Then $100 \mu \mathrm{l}$ of 3-(4,5-dimethylthiazol-2yl)-2,5-diphenyl tetrazolium bromide (MTT, $2 \mathrm{mg} / \mathrm{ml}$ in PBS; Sigma-Aldrich, Brazil) were added to each well and the plates were incubated for $4 \mathrm{~h}$ at $37^{\circ} \mathrm{C}$. Following incubation, the supernatants were removed and the formazan crystals formed were dissolved in $100 \mu \mathrm{l}$ of $100 \%$ DMSO. Absorbances were read at $540 \mathrm{~nm}$ using a spectrophotometer. All experiments were performed three times in triplicate. Citotoxicity was then classified as follows: (i) 0 - not cytotoxic (inhibition below 25\%); (ii) 1- slightly cytotoxic (inhibition between 25 and 50\%); (iii) 2-moderately cytotoxic (inhibition between 50 and 75\%) and (iv) 3-intensely cytotoxic (inhibition higher than 75\%). Besides statistical analysis, the results were also evaluated in accordance with ISO standard 10993-5.

\section{Investigation of Plant Components}

The crude hydro-alcoholic extract of T. catappa Linn, as well as FHEX, FAcOEt, and $\mathrm{FBuOH}$, were subjected to phytochemical analysis based on the tests proposed by Matos (1998) to search for phenols, tannins, flavones, xanthones, flavonols, flavanoids, and triterpene steroids. This survey aimed to identify the classes of natural products (called secondary or functional plant metabolites) present in this extract. 


\section{Fractionation of Extracts Using a Sephadex ${ }^{\circledR}$ LH-20}

After determining the antifungal activity of TcHE and its different fractions, the $\mathrm{FBuOH}(44.13 \mathrm{mg})$ fraction was sub-fractionated in a Sephadex ${ }^{\circledR}$ LH-20 (Sigma-Aldrich, St. Louis, MO, USA) column $(5 \times 100 \mathrm{~cm})$ using methanol (Merck, Darmstadt, Germany) as the mobile phase. For this, the eluate was pumped at a flow rate of $500 \mathrm{ml} / \mathrm{h}$ for $4 \mathrm{~h}$ and then, 15 SFs were collected (25 $\mathrm{ml} /$ tube). The SFs exhibiting the greatest antifungal activities were identified, mixed and fractionated. The antifungal effects of these resulting SFs were also assessed against Candida spp. via the agar diffusion and microdilution methods.

\section{Chemical Analysis}

Gas Chromatography Coupled to Mass Spectrometry with Electron Impact Ionization (GC/MS/EI)

TcHE, FHEX, FAcOEt, and $\mathrm{FBuOH}$ samples were derivatized with N,O-bis (trimethylsilyl) trifluoroacetamide with trimethylchlorosilane (BSTFA+TMCS, 99:1, v/v) (SigmaAldrich, St. Louis, MO, USA). The samples were analyzed using an Agilent 6890 gas chromatograph (Agilent Technologies, Inc., Santa Clara, CA) and mass spectrometry (Agilent 5973N MSD) with an HP-5 Agilent ${ }^{\circledR}(0.25 \mathrm{~mm} \times 30 \mathrm{~m} \times 0.25 \mu \mathrm{m})$ column under the following conditions: $230^{\circ} \mathrm{C}$ injection temperature, $250^{\circ} \mathrm{C}$ interface, $200^{\circ} \mathrm{C}$ ion source with a helium carrier gas flow of $1 \mathrm{ml} / \mathrm{min}$. The column oven temperature increased as follows: $5 \mathrm{~min}$ of heating $\left(70^{\circ} \mathrm{C}\right)$, gradient of $5^{\circ} \mathrm{C} / \mathrm{min}$ up to $310^{\circ} \mathrm{C}$.

\section{High-Performance Liquid Chromatography Coupled with Ultraviolet Spectroscopy (HPLC/UV)}

A total ion chromatogram (TIC) was obtained using an Agilent Varian ProStar HPLC system equipped with a ProStar 325 UV-Vis detector (ProStar 325, Varian, Palo Alto, USA) and a C18 column (Pursuit, Agilent Technologies, Inc., Santa Clara, CA, USA), which was protected with a guard column. For the mobile phase, pump A utilized Milli-Q water (Millipore-Merck, Darmstadt, Germany) acidified with $0.1 \%$ acetic acid; Pump C used HPLC-grade acetonitrile (Merck, Darmstadt, Germany) and pump B used methanol (HPLC grade, Merck, Darmstadt, Germany) to clean the column. The program used for elution was carried out from 0 to 15 min with gradient ranged from $95 \% \mathrm{~A}$ and $0.5 \% \mathrm{C}$ to $72 \% \mathrm{~A}$ and $28 \% \mathrm{C}$. Then the gradient ranged from $72 \% \mathrm{~A}$ and $28 \% \mathrm{C}$ to $32 \% \mathrm{~A}$ to $68 \% \mathrm{C}$ in the interval between 16 and $55 \mathrm{~min}$, reaching the concentration of $100 \%$ for $\mathrm{C}$ in the interval of 55-60 min. The detection of compounds of interest was performed at a wavelength $(\lambda)$ of $254 \mathrm{~nm}$, and the volume injected was $20 \mu \mathrm{l}$, with the mobile phase flow set at $0.6 \mathrm{ml} / \mathrm{min}$.

\section{Liquid Chromatography Coupled to Electrospray Ionization Mass Spectrometry in Positive Mode (HPLC-MS/MS/ES ${ }^{+}$)}

This analysis was performed to determine the molecular masses of positive ions detected and to identify the components present in $\mathrm{FBuOH}$ and its sub-fractions. The analyses were conducted using a 10AD-VP chromatographic system coupled with a Shimadzu SPD-M10AVP DAD detector (Shimadzu, Kyoto, Japan) and an Esquire 3,000 Plus-Ion Trap mass spectrometer
(Bruker Daltonics, GmbH, Bremen, Germany) equipped with a $4,000 \mathrm{~V}$ capillary, a nebulizer set at 27 psi, a drying gas flux of 7 $1 / \mathrm{min}$, and a temperature of $320^{\circ} \mathrm{C}$, in positive ion mode.

\section{Nuclear Magnetic Resonance of Hydrogen ( ${ }^{1} \mathrm{HNMR}$ )}

To identify the compounds present in $\mathrm{FBuOH}$ sub-fraction 10 (SF10-FbuOH), this sub-fraction was subjected to analysis via ${ }^{1} \mathrm{H}$ nuclear magnetic resonance using a $300-\mathrm{MHz}$ Varian Mercury Plus spectrometer (Varian Medical Systems, Inc., CA, USA) (7.05 $\mathrm{T})$ in $\mathrm{CD}_{3} \mathrm{OD}$. Chemical shifts $(\delta)$ were reported in ppm using tetramethylsilane (TMS) as an internal reference standard, and coupling constants ( $\mathrm{J}$ ) were given in Hz. The ATB (Automation Triple Resonance Broadband) probe (5 $\mathrm{mm}$ inner diameter) was used at room temperature and pulse 45 to detect ${ }^{1} \mathrm{H}$.

\section{Statistical Analysis}

Each experiment was performed in triplicate and results were expressed as mean \pm standard deviation (SD). To evaluate the effects of the various fractions and sub-fractions on fungal growth, we initially applied the Shapiro-Wilk test for normality. Once the results were confirmed to be normally distributed, the data were analyzed by ANOVA followed by Tukey's test. Data obtained from PBMC cell viability test were analyzed by ANOVA followed by Dunnet's test. The significance level was set at $5 \%$ for all tests.

\section{RESULTS}

\section{Distribution of Candida Species from Mucosal Tissues}

This study included 52 patients diagnosed with AIDS. Candida cells were found in the oral cavities of $83 \%$ (43) patients, with some of them $(18.6 \%)$ colonized with multiple Candida spp. As a result, 51 yeast strains were isolated. Of those, $56 \%$ were C. albicans (29/51), 12\% were C. tropicalis $(6 / 51)$, $12 \%$ were C. krusei (6/51), 8\% were C. glabrata (4/51), 4\% were C. famata (2/51), $4 \%$ were C. parapsilosis (2/51), and $4 \%$ were C. guilliermondii (2/51). The four most prevalent isolates of Candida spp. were investigated in the antifungal activity assays.

\section{Plant Material: Yield and Phytochemical Analysis}

Yields obtained for TcHE, FHEX, FAcOEt, and FBuOH were depicted in Table 1 with $\mathrm{FBuOH}$ presenting the lowest one. T. catappa TcHE, FHEX, FAcOEt, and $\mathrm{FBuOH}$ were subjected to phytochemical screening according to the method described

TABLE 1 | The dry weights and yields of the hydro-alcoholic extract and its fractions.

\begin{tabular}{lcccc}
\hline Weight of dry leaves & TcHE & FHEX & FAcOEt & FBuOH \\
\hline $1 \mathrm{~kg}(570 \mathrm{ml})$ & $46.17 \mathrm{~g}$ & $2.123 \mathrm{~g}$ & $2.317 \mathrm{~g}$ & $1.067 \mathrm{~g}$ \\
Yield & $5.77 \%$ & $0.26 \%$ & $0.28 \%$ & $0.13 \%$ \\
\hline
\end{tabular}

TCHE, crude hydro-alcoholic extract of T. catappa L.; FHEX, hexane fraction; FAcOEt, ethyl acetate fraction; $\mathrm{FBuOH}, \mathrm{N}$-butanol fraction. 
by Matos (1998). The analysis revealed the presence of phenols, tannins, flavones, flavonols, flavonoids, and triterpenes sterols (Table 2).

\section{Antifungal Activity}

Antifungal assays were performed against different clinical and reference strains of Candida. Both the TcHE and its fractions

TABLE 2 | Phytochemical analysis of the hydro-alcoholic extract and its fractions.

\begin{tabular}{lcccc}
\hline \multirow{2}{*}{ Compounds class } & \multicolumn{4}{c}{ Terminalia catappa extracts } \\
\cline { 2 - 5 } & TcHE & FHEX & FAcOEt & FBuOH \\
\hline Phenols & + & + & + & + \\
Tannins & + & - & + & + \\
Flavones, xanthones, flavonols & + & + & - & + \\
Flavonoids & + & - & - & + \\
Triterpenes steroids & + & + & - & - \\
\hline
\end{tabular}

TCHE, crude hydro-alcoholic extract of T. catappa L.; FHEX, hexane fraction; FAcOEt, ethyl acetate fraction; $\mathrm{FBUOH}, \mathrm{N}$-butanol fraction; (+), presence of substance; (-), absent of substance. were antifungal against all the tested strains of Candida when assessed in the microdilution method (Table 3). However, their antifungal potencies varied between strains. MIC values ranged from 1.5 to $6 \mathrm{mg} / \mathrm{ml}$ for FHEX, 0.75 to $3 \mathrm{mg} / \mathrm{ml}$ for $\mathrm{FBuOH}$, 0.75 to $6 \mathrm{mg} / \mathrm{ml}$ for FAcOEt and 0.75 to $12 \mathrm{mg} / \mathrm{ml}$ for TcHE (Table 3). The $\mathrm{MIC}_{90}$ (minimum concentration able to inhibit $90 \%$ of strains) for TcHE, FHEX and FAcOEt was $3 \mathrm{mg} / \mathrm{ml}$, but $1.5 \mathrm{mg} / \mathrm{ml}$ for $\mathrm{FBuOH}$. FBuOH presented the lowest MIC values (Table 3).

Amphotericin B, fluconazole, FHEX, FAcOEt, and TcHE were compared to $\mathrm{FBuOH}$ in relation to the capacity of Candida growth inhibition. Growth inhibition assays showed that $\mathrm{TcHE}, \mathrm{FBuOH}$, and $\mathrm{FAcOEt}(1.5 \mathrm{mg} / \mathrm{ml})$ presented the best antifungal activities against all the tested reference strains of Candida spp with percentage of inhibitions as high as $100 \%$ (Figures 1A-C). Significant differences were observed across fractions with FHEX being the least active $(p<0.01$ or $p<0.0001$ depending on species, Figures 1A-C). Of note, $\mathrm{TcHE}, \mathrm{FBuOH}$, and $\mathrm{FAcOEt}$ were more effective than fluconazole $(p<0.0001)$ and amphotericin B $(p<0.05)$ (Figures 1A-C). C. krusei ATCC 6258 was sensitive dose dependent (SDD) to fluconazole (Figure 1C; MIC value of $16 \mu \mathrm{g} / \mathrm{ml})$.

TABLE 3 | Minimum inhibitory concentrations of amphotericin B, fluconazole, FHEX, FBuOH, FAcOEt, TcHE against Candida spp.

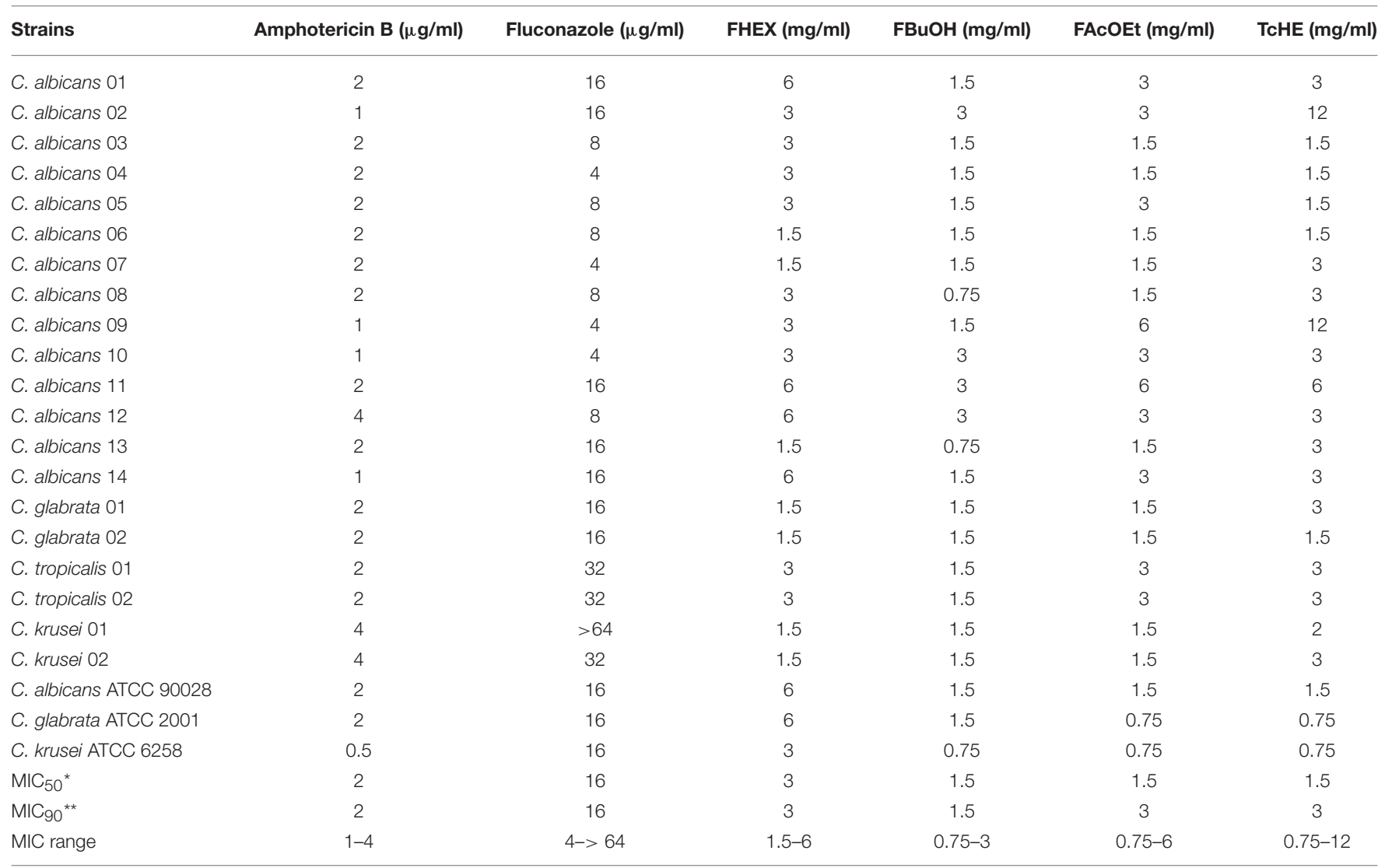

${ }^{*} M I C_{50}$, MIC value that inhibited $50 \%$ of the strains.

${ }^{* *}$ MIC 90, MIC value that inhibited $90 \%$ of the strains. 
When tested against C. albicans ATCC 90028, MIC values were of $6 \mathrm{mg} / \mathrm{ml}$ for FHEX, and $1.5 \mathrm{mg} / \mathrm{ml}$ for $\mathrm{FBuOH}$, FAcOEt, and TcHE. Also, MIC values were of $6 \mathrm{mg} / \mathrm{ml}$ for FHEX, 1.5 $\mathrm{mg} / \mathrm{ml}$ for $\mathrm{FBuOH}$, and $0.75 \mathrm{mg} / \mathrm{ml}$ for FAcOEt and TcHE against C. glabrata ATCC 2001. FHEX (3 mg/ml), FBuOH, FAcOEt, and
TcHE $(0.75 \mathrm{mg} / \mathrm{ml})$ were all able to inhibit C. krusei ATCC 6258 growth (Table 3 ).

Figures 2A-D represented some of the best results of antifungal potential of TcHE and its fractions against four clinical isolates, one from each species, at $1.5 \mathrm{mg} / \mathrm{ml}$. FBuOH
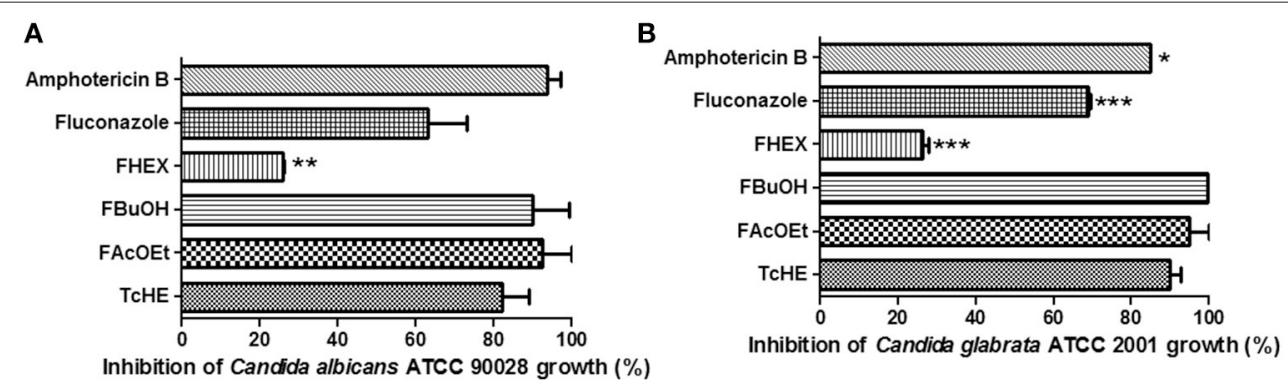

C

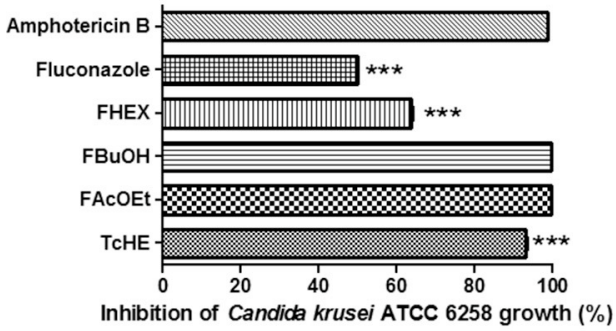

FIGURE 1 | Inhibitory effect of fluconazole and amphotericin B (clinically used antifungal agents), TcHE, FAcOEt, FBuOH, and FHEX on Candida reference strains growth. (A) Candida albicans ATCC 90028; (B) Candida glabrata ATCC 2001; (C) Candida krusei ATCC 6258. The concentrations used were: $1.5,8$, and $2 \mu \mathrm{g} / \mathrm{ml}$ for TcHE and its fractions, fluconazole and amphotericin B, respectively. Inhibitory action of each substance was compared to that of FBuOH. ${ }^{*} p<$ $0.05,{ }^{* \star} p<0.01$, and ${ }^{* \star *} p<0.0001$ were considered to be significant.

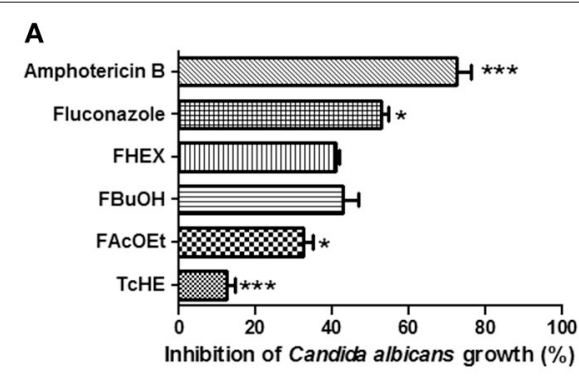

C

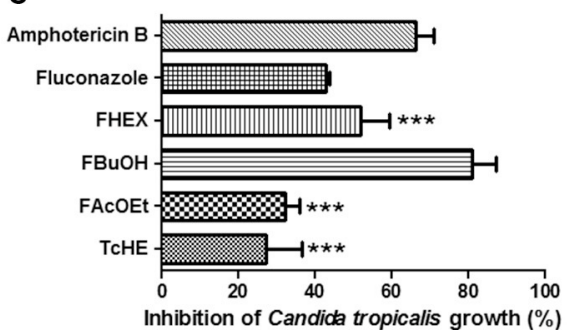

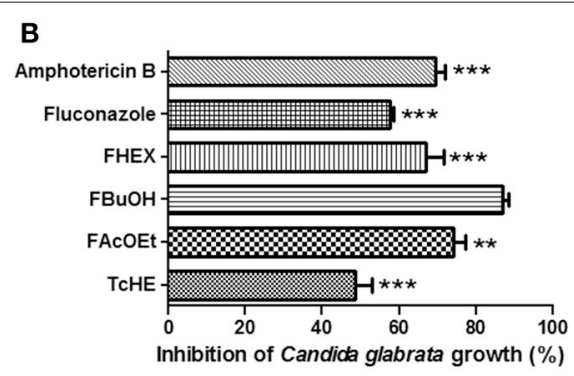

D

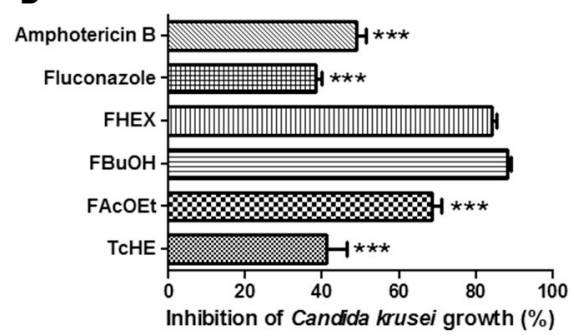

FIGURE 2 | Inhibitory effect of fluconazole and amphotericin B (clinically used antifungal agents), TcHE, FAcOEt, FBuOH, and FHEX on Candida clinical samples growth. (A) Candida albicans; (B) Candida glabrata; (C) Candida tropicalis; (D) Candida krusei. The concentrations used were: 1.5, 8, and $2 \mu \mathrm{g} / \mathrm{ml}$ for TcHE and its fractions, fluconazole and amphotericin B, respectively. Inhibitory action of each substance was compared to that of FBuOH. ${ }^{*} p<0.05,{ }^{* *} p<0.01$, and ${ }^{\star \star *} p<0.0001$ were considered to be significant. 
showed better antifungal activity than TcHE $(p<0.0001)$ and FAcOEt $(p<0.05)$ against $C$. albicans clinical strain (Figure 2A). Amphotericin B $(p<0.0001)$ and fluconazole $(p<0.05)$ presented higher activity in comparison to that observed for $\mathrm{FBuOH}$ (Figure 2A). Similarly, FBuOH presented the best activity on C. glabrata and C. tropicalis clinical isolates $(p<0.0001$, Figures 2B-C). These effects were even more pronounced than those observed for either fluconazole or amphotericin B $(p<0.0001$, Figures 1B,C). When evaluated against $C$. krusei clinical isolates, $\mathrm{FBuOH}$ and FHEX were the most effective, followed by FAcOEt ( $p<0.0001$, Figure 2D). C. krusei and $C$. tropicalis clinical samples were SDD to fluconazole (Figures 2C-D), with MIC values of $16 \mu \mathrm{g} / \mathrm{ml}$ (Table 3).

As $\mathrm{FBuOH}$ was found to exhibit the best antifungal activity, we next assessed the antifungal properties of its sub-fractions (SF 1-15), by using the agar diffusion test. Figure 3 illustrates the test results for a clinical isolate. Of those sub-fractions, only SF $7-14$ were antifungal $(112 \mu \mathrm{g} / \mathrm{ml})$ (Figure 3). SF 10 $(\mathrm{SF} 10-\mathrm{FBuOH})$ presented the largest inhibition zone $(p<0.001$, Figure 3). We next assessed the antifungal actions of SF10$\mathrm{FBuOH}(0.2-56 \mu \mathrm{g} / \mathrm{ml})$ in the microdilution test against four clinical isolates and reference strains.

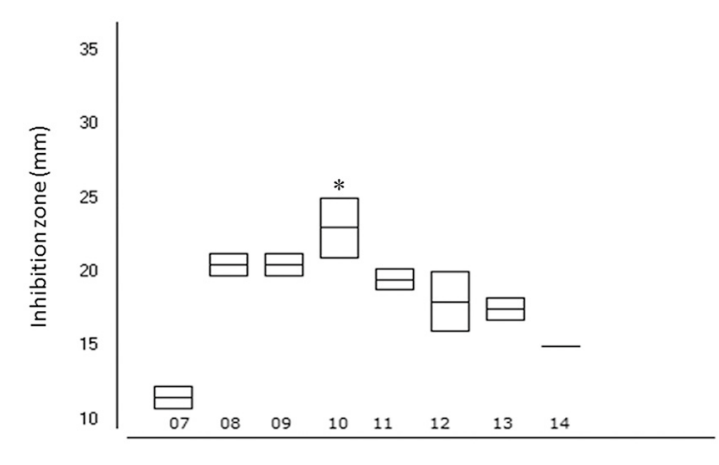

Subfractions of the n-butanol fraction

FIGURE 3 | Boxplots of the mean values and standard deviations of the sizes of the inhibition zones caused by activity of specific $\mathrm{FBuOH}$ sub-fractions (SF 7-14). ANOVA and Tukey's test $(p<0.001)$ showed that the SF10-FBuOH had a significant greater inhibition zone size than the other sub-fractions tested $\left({ }^{*} p<0.05\right)$.
SF10-FBuOH MIC values ranged from 7 to $56 \mu \mathrm{g} / \mathrm{ml}$, with the lowest value being registered against the $C$. albicans isolate. Both the $\mathrm{MIC}_{50}$ (minimum concentration able to inhibit $50 \%$ of strains) and the $\mathrm{MIC}_{90}$ (minimum concentration able to inhibit $90 \%$ of strains) were $28 \mu \mathrm{g} / \mathrm{ml}$ (Table 5).

$\mathrm{SF} 10-\mathrm{FBuOH}$ was then fractionated and the resultant subfractions (SF 10.1-10.10) were evaluated in the agar diffusion method against C. albicans ATCC 90028 and two C. albicans clinical isolates. Only SF 10.5-10.10 were antifungal, with SF 10.5 being the most active sub-fraction $(p<0.05)$. Table 4 depicted the results when SF $10.5-\mathrm{SF} 10.10$ were tested at $96 \mu \mathrm{g} / \mathrm{ml}$. This antifungal action was further confirmed in the microdilution test. SF $10.5 \mathrm{MIC}$ values ranged from 6 to $48 \mu \mathrm{g} / \mathrm{ml}$ with the lowest value being registered against the $C$. tropicalis isolate. $\mathrm{MIC}_{50}$ was of $24 \mu \mathrm{g} / \mathrm{ml}$ and $\mathrm{MIC}_{90}$ was $48 \mu \mathrm{g} / \mathrm{ml}$ (Table 5).

\section{PBMC Viability}

The cytotoxic effects of TcHE were evaluated on PBMC. Overall, TcHE was not cytotoxic, only reducing cell viability at very high concentrations $(5-10 \mathrm{mg} / \mathrm{ml})$ in comparison with vehicle-treated controls $(p<0.05$, Figure 4$)$.

TABLE 5 | Minimum inhibitory concentration $(\mu \mathrm{g} / \mathrm{mL})$ of amphotericin B, fluconazole, SF10-FBuOH and SF- 10.5 against Candida spp.

\begin{tabular}{|c|c|c|c|c|}
\hline Strains & Amphotericin B & Fluconazole & SF10-FBuOH & SF-10.5 \\
\hline C. albicans 02 & 8 & 16 & 7 & 24 \\
\hline C. glabrata 01 & 8 & 16 & 28 & 24 \\
\hline C. tropicalis 01 & 8 & 32 & 28 & 6 \\
\hline C. krusei 02 & 8 & $>64$ & 28 & 48 \\
\hline $\begin{array}{l}\text { C. albicans ATCC } \\
90028\end{array}$ & 8 & 32 & 28 & 24 \\
\hline $\begin{array}{l}\text { C. glabrata ATCC } \\
2001\end{array}$ & 8 & 64 & 14 & 24 \\
\hline $\begin{array}{l}\text { C. krusei ATCC } \\
6258\end{array}$ & 4 & 16 & 14 & 48 \\
\hline $\mathrm{MIC}_{50}{ }^{*}$ & 8 & 32 & 28 & 24 \\
\hline $\mathrm{MIC}_{90}{ }^{* \star}$ & 8 & 64 & 28 & 48 \\
\hline MIC range & $4-8$ & $16->64$ & $7-28$ & $6-48$ \\
\hline
\end{tabular}

${ }^{*} \mathrm{MIC}_{50}$, MIC value that inhibited $50 \%$ of the strains.

${ }^{* *}$ MIC 90, MIC value that inhibited $90 \%$ of the strains.

TABLE 4 | Antifungal potential of sub-fractions SF 10.5, SF 10.6, SF 10.8, SF 10.9, and SF 10.10, derived from sub-fraction SF10-FBuOH, evaluated by the antifungal agar diffusion test against Candida albicans ATCC 90028 and two clinical specimen of Candida albicans.

\begin{tabular}{|c|c|c|c|c|c|c|}
\hline \multirow[t]{2}{*}{ C. albicans strains } & \multicolumn{5}{|c|}{ SF10 sub-fractions } & \multirow[b]{2}{*}{ FLZ } \\
\hline & SF 10.5 & SF 10.6 & SF 10.8 & SF 10.9 & SF 10.10 & \\
\hline ATCC 90028 & $15 \pm 0.81$ & $12.33 \pm 1.24$ & $11.33 \pm 1.24$ & $9.67 \pm 0.47$ & $8.67 \pm 1.24$ & $6.33 \pm 0.44$ \\
\hline Сa 02 & $15 \pm 1.0$ & $14 \pm 2.64$ & $14.66 \pm 1.52$ & $10.66 \pm 1.15$ & $9.97 \pm 0.46$ & $5.33 \pm 1.25$ \\
\hline $\mathrm{Ca} 04$ & $15.33 \pm 1.25$ & $11.67 \pm 1.24$ & $10.66 \pm 1.69$ & $9.33 \pm 1.24$ & $9.33 \pm 0.47$ & $10.43 \pm 0.62$ \\
\hline
\end{tabular}

Inhibition zones size is expressed in $\mathrm{mm}$; FLZ, fluconazole $(64 \mu \mathrm{g} / \mathrm{ml})$.

The antifungal activity was obtained from three independent experiments done in triplicate at a concentration of $96 \mu \mathrm{g} / \mathrm{ml}$.

The ANOVA test was applied where each value represents the mean \pm the standard deviation (SD) of the inhibition zones size (mm). 


\section{Chemical Analysis and Identification of the Components of FBuOH and SF10-FBuOH}

Total ion chromatography (TIC) of SF10-FBuOH revealed a chromatographic peak with a retention time of $30 \mathrm{~min}$ corresponding to gallic acid. The probability of this compound being gallic acid was $90 \%$ according to the NIST/EPA/NIH Mass Spectral Library (National Institute of Standards and Technology, Gaithersburg, MD).

Analysis of $\mathrm{FBuOH}$ using the HPLC-DAD/MS/MS/ESI ${ }^{+}$ system revealed 10 chromatographic peaks with two major peaks: peak number 4 , with a retention time (Rt) of 10.943 min $(28.639 \%)$ and peak 7 with a Rt of $13.839 \min (21.089 \%)$

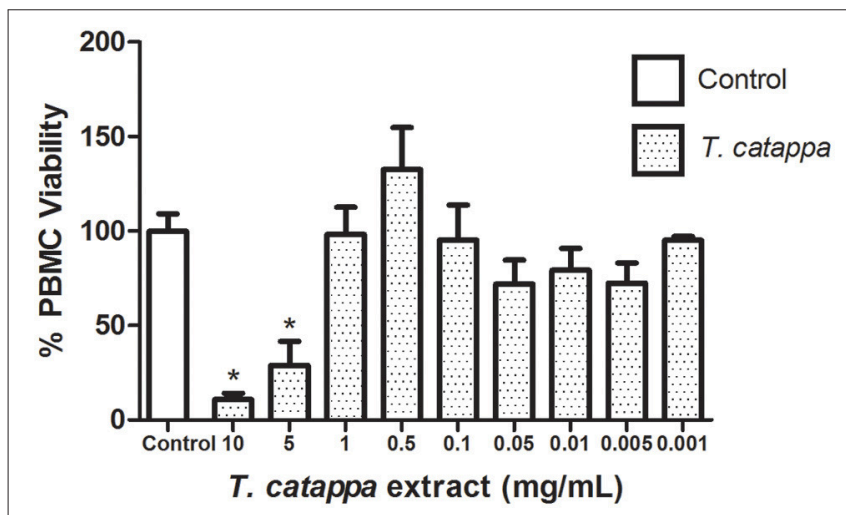

FIGURE 4 | PBMC cell viability after exposure to different concentrations of TcHE. Symbol (*) represents statistical differences between the control and experimental groups (ANOVA one way followed by Dunnet test, $p<0.05$ ).
(Figure 5). These peaks were accompanied by their respective absorption spectra in the ultraviolet region (Figure 6). The maximum wavelengths $(\max \lambda)$ of the absorption bands for all peaks were characteristic of the galagil chromophore, at 218, 260 , and $379 \mathrm{~nm}$ and demonstrated varying intensities for the absorption band at $218 \mathrm{~nm}$ (Figure 6). Thus, $\mathrm{FBuOH}$ of T. catappa is rich in compounds found in the ellagitannins (hydrolyzable tannins) class.

The MS1/MS2/ES ${ }^{+}$system was used in $\mathrm{FBuOH}$ and SF10$\mathrm{FBuOH}$, which allowed us to determine the molecular weights of the positive ions detected and to identify the components in subfractions rich in ellagitannins and other classes of compounds, such as C-flavonoid glycosides (Figure 7). In the chromatogram for $\mathrm{FBuOH}$, the ion $\left[\mathrm{M}+\mathrm{H}^{+}\right]$detected at the MS RT of 9.2 min showed a mass to charge $(\mathrm{m} / z)$ ratio of $\left[\mathrm{M}+\mathrm{H}^{+}\right]=1.103$, which was compatible with the molecular formula $\mathrm{C}_{48} \mathrm{H}_{30} \mathrm{O}_{31}$ for which $\mathrm{M}=1,102 \mathrm{Da}$, which was identified as an ellagitannin acid derived from punicalagin. The ion $\left[\mathrm{M}+\mathrm{H}^{+}\right]$detected at the MS1 RT of $9.5 \mathrm{~min}$ had an $\mathrm{m} / z$ ratio of $\left[\mathrm{M}+\mathrm{H}^{+}\right]=783$, detected for fragments with $\mathrm{m} / z=765$ (100\%), $\mathrm{m} / z=680$ and $\mathrm{m} / z=621$. This mass was compatible with the molecular formula $\mathrm{C}_{34} \mathrm{H}_{22} \mathrm{O}_{22}$, for which $\mathrm{M}=782 \mathrm{Da}$, and was identified as an ellagitannin acid derivative of punicalin.

The structural formulas proposed for the compounds in $\mathrm{FBuOH}$ were shown in Figure 8 based on LC/MS/ES ${ }^{+}$analysis of the ions detected with retention times in the range of 9.2-11.5 min in $\mathrm{FBuOH}$.

The ${ }^{1}$ HNMR spectra demonstrated the chemical shift of signals $(\delta$, or $\mathrm{ppm})$, with data for $\mathrm{SF} 10-\mathrm{FBuOH}$ revealing two additional intense signals at $\delta=3.3$ and 4.8, which were derived from the $\mathrm{CH}_{3} \mathrm{OH}$ and $\mathrm{H}_{2} \mathrm{O}$ non-deuterated solvents. The signal

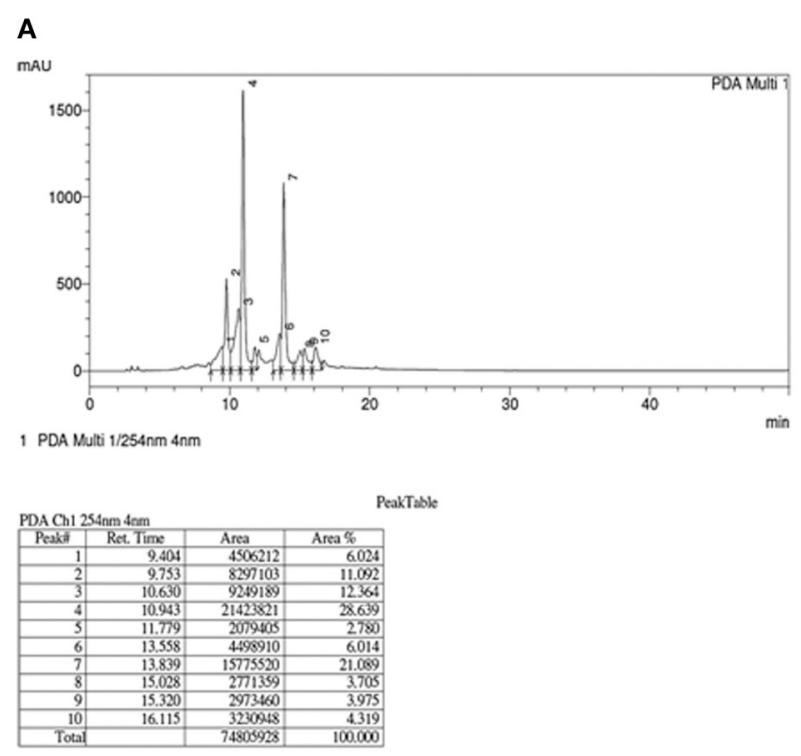

B
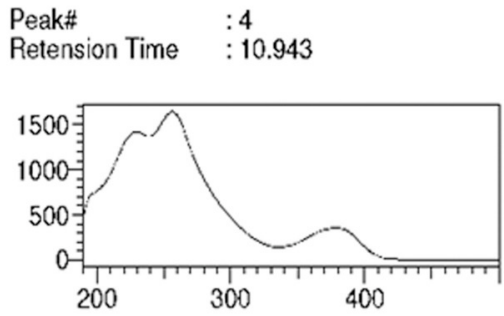

$\begin{array}{ll}\text { Peak\# } & : 7 \\ \text { Retension Time } & : 13.013\end{array}$

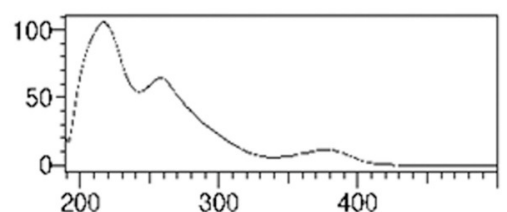

FIGURE 5 | Analysis of LC/DAD and HPLC/DAD data for SF10-FBuOH. (A) The chromatographic profile and a table containing the RTs and areas (\%) of peaks detected at $254 \mathrm{~nm}$. HPLC detected 10 peaks in FBuOH, with RTs ranging from 9.404 to $16.115 \mathrm{~min}$. The major peaks were peaks 4 (RT = $10.943 \mathrm{~min})$ and 7 (RT $=13.013 \mathrm{~min})$. (B) The ultraviolet absorption spectra of the major peak was at 4:07. 
A

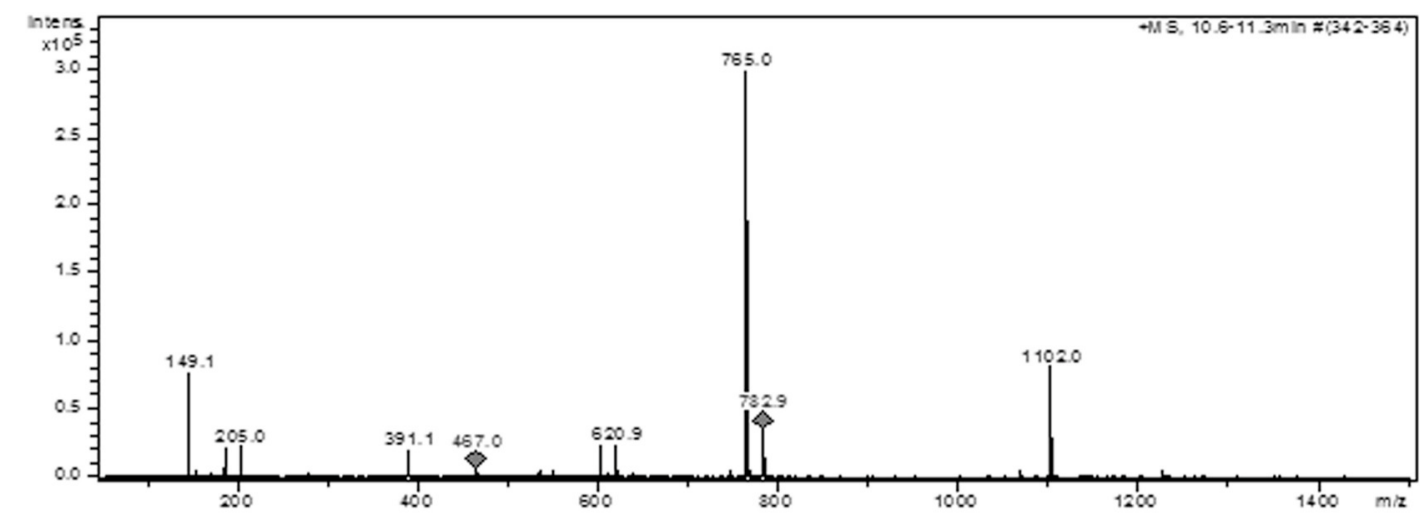

B

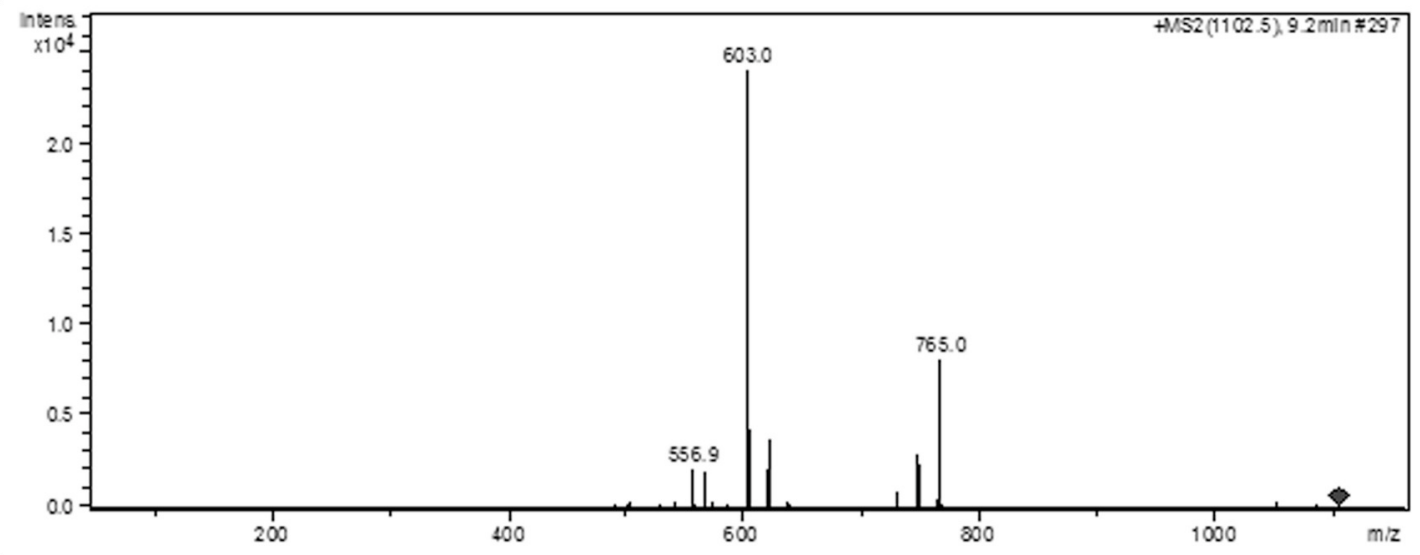

C

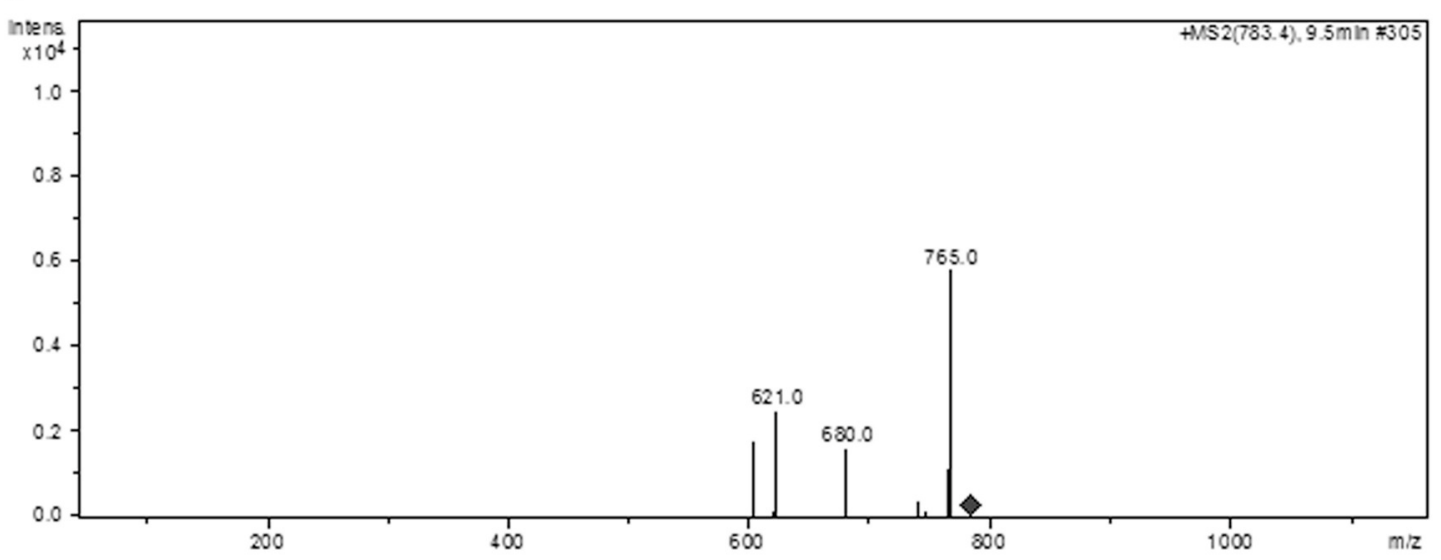

FIGURE 6 | An analysis of the LC/MS/MS/IES data for SF10-FBuOH. (A) MS2 with ions detected by TIC. (B) The MS2 peak with RT=9.2 min (punicalagin). (C) The EM2 peak with $\mathrm{RT}=9.5 \mathrm{~min}$ (punicalin).

in the $\delta=6.4-6.82$ region corresponded to hydrogens of the aromatic ring, and the signal in the $\delta=3.98-4.2$ region referred to the methinic hydrogens of a sugar moiety, while $\delta=2.15$ in the form of multiple signals was assigned to the sugar methylene group $\left(\mathrm{CH}_{2}\right)$ (Figure 8).

The expansion of the ${ }^{1} \mathrm{HNMR}$ spectra of the $\delta$ 8.4-3.8 region revealed signals of chemical shift at $\delta=8.5$ attributed to one acid hydroxyl $(\mathrm{OH})$, confirming the presence of free carboxyl groups for the structure with $M=1,102 \mathrm{Da}$. Signals with different coupling constants were also identified in the $\delta$ 5.5-4.9 region which could be attributed to the anomeric hydrogens of the $\alpha \beta$ structures derived from punicalin and punicalagin. Therefore, chromatographic studies of $\mathrm{FBuOH}$ and its sub-fractions revealed a compound formed by hydrolyzable tannins (punicalin and punicalagin), gallic acid and C-flavonoid glycosides. 
A

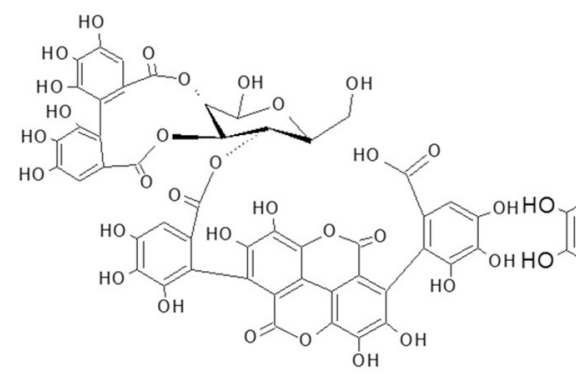

$\mathrm{m} / \mathrm{z}=1102\left(\mathrm{C}_{48} \mathrm{H}_{28} \mathrm{O}_{31}\right)$ (Punicalagin)

c

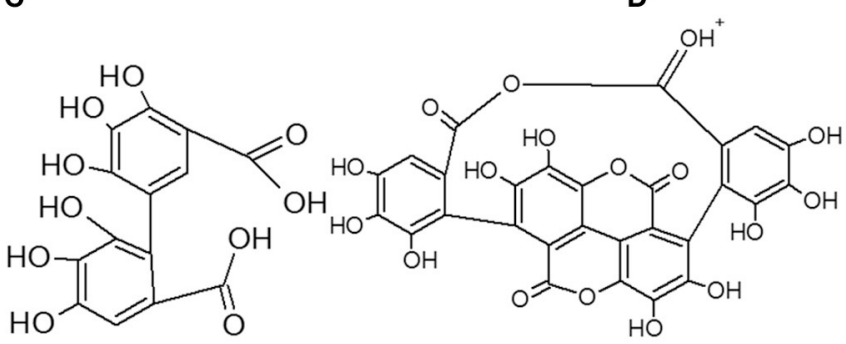

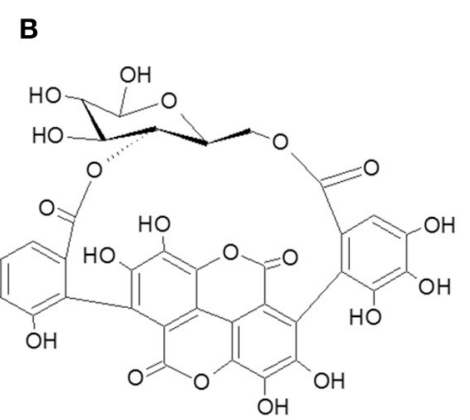

$\mathrm{m} / \mathrm{z}=782\left(\mathrm{C}_{34} \mathrm{H}_{22} \mathrm{O}_{22}\right)$ (Punicalin) $\mathrm{m} / \mathrm{z}=338\left(\mathrm{C}_{14} \mathrm{H}_{10} \mathrm{O}_{10}\right)$ (Ellagicacid)

E

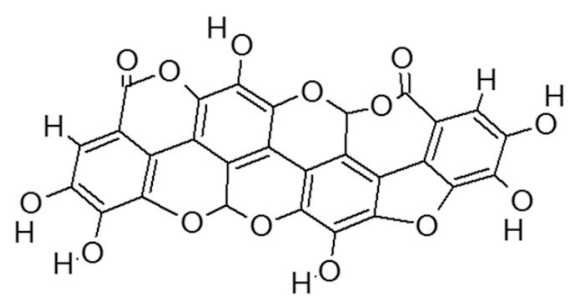

(Ellagicacid) $\mathrm{m} / \mathrm{z}=580\left(\mathrm{C}_{28} \mathrm{H}_{10} \mathrm{O}_{14}\right)$ fora o ion $[\mathrm{M}+\mathrm{H}+]=571$

$$
\mathrm{m} / \mathrm{z}=621\left[\mathrm{C}_{28} \mathrm{H}_{12} \mathrm{O}_{17}=620+\mathrm{H}^{+}\right]
$$

$\mathbf{F}$

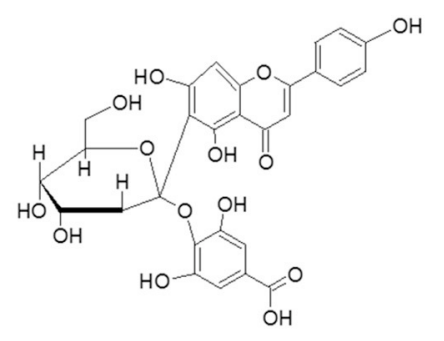

$\mathrm{MS}^{2} \quad \mathrm{ES}^{+}\left[\mathrm{M}+\mathrm{H}^{+}\right]=585 \mathrm{Da}$ toIsovitexindlerivated $\left(2^{\prime \prime}-\mathrm{O} \quad-\right.$ galloyl)

FIGURE 7 | Structures proposed by the results of the MS/MS/ES ${ }^{+}$analysis for ions detected at RTs ranging from 9.2 to $11.5 \mathrm{~min}$ in SF10-FBuOH. (A) The pseudomolecular ion $\left[\mathrm{M}+\mathrm{H}^{+}\right]=1,103(\mathrm{RT}=9.2 \mathrm{~min})$ and molecular mass of $\mathrm{M}=1,102$ for the molecular formula $\mathrm{C}_{48} \mathrm{H}_{28} \mathrm{O}_{31}$, which was identified as an ellagitannin acid derivative of punicalagin. (B) The pseudomolecular ion $\left[\mathrm{M}+\mathrm{H}^{+}\right]=783(\mathrm{RT}=9.3 \mathrm{~min}$ ) with a molecular mass of $\mathrm{M}=782$ for molecular formula $\mathrm{C}_{34} \mathrm{H}_{22} \mathrm{O}_{22}$, identified as punicalin. (C) The pseudomolecular ion $\left[\mathrm{M}+\mathrm{H}^{+}\right]=338 \mathrm{M}$ for the formula $\mathrm{C}_{14} \mathrm{H}_{10} \mathrm{O}_{10}$, which was identified as ellagic acid dihydrate. (D,E) Ellagic acid derivative. (F) Isovitexin derivative (2" $-\mathrm{O}$-galloyl).

\section{DISCUSSION}

This study confirmed the high frequency of oral candidiasis in hospitalized patients with AIDS (83\%), as reported in other studies, demonstrating the development of one or more fungal infections in $80-95 \%$ of patients during the course of their illness (Bouza and Muñoz, 2008; Junqueira et al., 2012). C. albicans was the most prevalent species (56\%), while the prevalence of all "non-albicans" Candida spp. was 44\%, which is in agreement with other studies (Favalessa et al., 2010; de Paula et al., 2015).

In general, patients with HIV/AIDS manifest approximately five episodes of oral candidiasis per year (Favalessa et al., 2010). Frequent episodes of fungal infection in immunosuppressed patients and the use of antifungal drugs have selected for fungal 


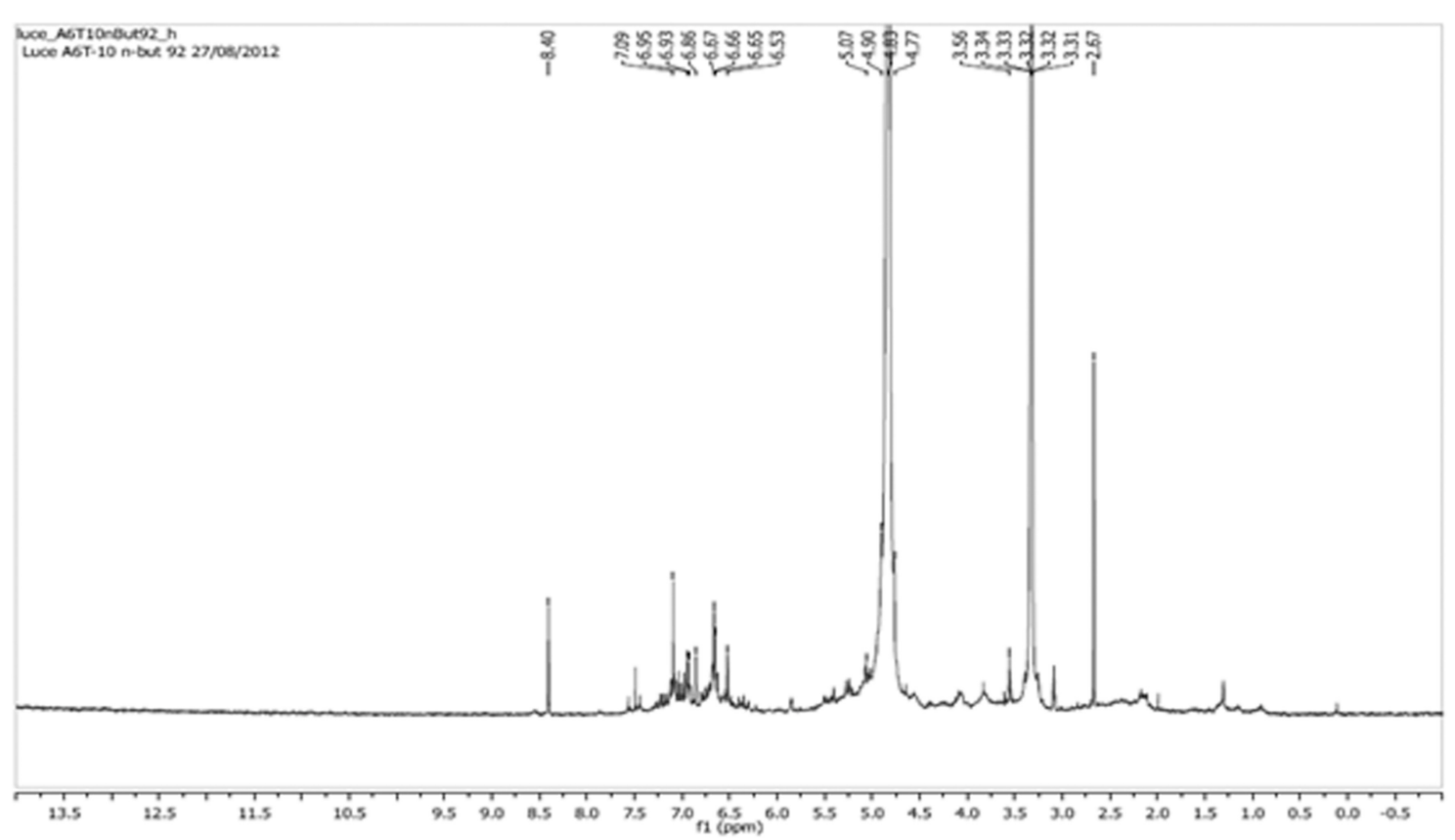

FIGURE 8 | The nuclear magnetic resonance spectrum of hydrogen $\left({ }^{1} \mathrm{H}\right)$ detected using a $300-\mathrm{MHz}$ Varian instrument in CD3 OD. The chemical shift signals ( $\delta$ or dpi) are shown for SF10-FBuOH.

strains resistant to antifungal drugs. In this study, fluconazole inhibited less than $50 \%$ of all Candida strains tested, confirming the development of fungal resistance in hospitalized patients with AIDS.

The increased incidence of antimicrobial-resistant Candida isolates has highlighted the need for novel and more potent therapies against this microorganism. T. catappa L. is a plant species that contains a wide variety of chemical components (Lin et al., 2001; Kinoshita et al., 2007; Naitik et al., 2012) and is widely used in the traditional medicine in India, Malaysia, and Indonesia. However, studies addressing the antifungal properties of T. catappa are scarce and little is known on the anti-Candida activities of hydro-alcoholic extracts obtained from T. catappa leaves. Recently, the crude ethanolic or aqueous extract from the leaves of T. catappa L. was suggested to be more effective against bacteria than Candida spp. (Jagessar and Alleyne, 2011). This poor effect was attributed to the lower concentration of substances active against filamentous fungi and C. albicans (Jagessar and Alleyne, 2011; Mandloi et al., 2013) in these preparations. Herein, we present novel and important evidence on that the TcHE is antifungal against Candida spp., and that this effect is due to the presence of antimicrobial compounds in the $\mathrm{FBuOH}$ fraction. Also, TcHE had not cytotoxic actions on PBMC.

The results obtained demonstrate that $\mathrm{FBuOH}$ and FAcOEt are more effective than TcHE and FHEX in reducing Candida spp. growth (>90\%). Of note, $\mathrm{FBuOH}$ actions were greater than those observed for FAcOEt, as it presented the lowest MIC values. Accordingly, fractionation of $\mathrm{FBuOH}$ showed its subfractions SF7-14 present potent antifungal activities, specially, $\mathrm{SF} 10-\mathrm{FBuOH}$; suggesting the compounds recovered in this sub-fraction exhibit superior antifungal activity. The antifungal activity of SF10-FBuOH was further confirmed by isolation of SF10.5, a sub-fraction of SF10-FBuOH which presented potent antimicrobial actions against Candida spp.

The chemical analysis of SF10-FBuOH detected the presence of hydrolysable tannins (punicalin and punicaligin), gallic acid and C-flavonoid glycosides. It was previously demonstrated that hydrolysable tannins, also called ellagitannins, are the major chemical constituents of T. catappa leaves and that they have been linked to the antitumor (Chen et al., 2000) and antioxidant activities attributed to this plant (Kinoshita et al., 2007). The same group of compounds has been associated with a strong antimicrobial activity against bacteria and yeast (Lim et al., 2006). This effect was suggested to involve the precipitation of proteins or the removal of metal and hydrogen ions from microbial enzymes, thereby modifying vital metabolic processes in these microrganisms (Okuda, 2005; Costa et al., 2008). In addition to these hydrolysable tannins, both gallic acid and the glycosylated phenols found in $\mathrm{FBuOH}$ may contribute to its antifungal activity. This is supported by findings in that the gallic acid obtained from the air-dried mature Galla rhois methanolic extract and other plants is antimicrobial (Ahn et al., 2005; Chanwitheesuk et al., 2007). Glycosylated phenolic compounds isolated from natural sources possess antifungal properties of interest. Particularly, phenolic acids have shown promising in vitro and in vivo activity against Candida species (Ozcelik et al., 2011; Teodoro et al., 2015). Flavonoids, especially their glycosides, are of great general interest due to their diverse bioactivity. Flavonoid C-glycosides, obtained from different types of plans, 
have shown significant antioxidant activity, anticancer, and antitumor activity, hepatoprotective activity, anti-inflammatory activity, anti-diabetes activity, antiviral activity, antibacterial, and antifungal activity, and other biological effects (Xiao et al., 2016).

In conclusion, the $\mathrm{FBuOH}$ obtained from the TcHE of T. catappa L. leaves is a potent antifungal against Candida spp., rich in hydrolysable tannins, gallic acid and glycosylated phenols. Also, the low cytotoxic effects of TcHE support the use of $\mathrm{FBuOH}$ or its derived sub-fractions and/or compounds as alternative therapies for Candida-induced infections.

\section{AUTHOR CONTRIBUTIONS}

$\mathrm{CM}$ conceived and designed the work and drafted the manuscript; AM, EF, and JS revising the work critically for important intellectual content and drafted the manuscript; AT was responsible for contact with patients and sample collection;

\section{REFERENCES}

Ahn, Y. J., Lee, H. S., Oh, H. S., Kim, H. T., and Lee, Y. H. (2005). Antifungal activity and mode of action of Galla rhois-derived phenolics against phytopathogenic fungi. Pestic. Biochem. Physiol. 30, 105-112. doi: 10.1016/ j.pestbp.2004.10.003

Anand, A. V., Divya, N., and Kotti, P. P. (2015). An updated review of Terminalia catappa. Pharmacogn. Rev. 9, 93-98. doi: 10.4103/0973-7847.162103

Annapurna, C. S., Prince, C. N., Sivaraj, S., and Ali, I. M. (2012). Oral manifestations of HIV patients in South Indian population. J. Pharm. Bioallied. Sci. 4, S364-S368. doi: 10.4103/0975-7406.100272

Bouza, E., and Muñoz, P. (2008). Epidemiology of candidemia in intensive care units. Int. J. Antimicrob. Agents 32, S87-S91. doi: 10.1016/ S0924-8579(08)70006-2

Chanwitheesuk, A., Teerawutgulrag, A., Kilburn, J. D., and Rakariyatham, N. (2007). Antimicrobial gallic acid from Caesalpinia mimosoides Lamk. Food Chem. 100, 1044-1048. doi: 10.1016/j.foodchem.2005.11.008

Chen, P. S., and Li, J. H. (2006). Chemopreventive effect of punicalagin, a novel tannin component isolated from Terminalia catappa on H-ras-transformed NIH3T3 cells. Toxicol. Lett. 163, 44-53. doi: 10.1016/j.toxlet.2005.09.026

Chen, P. S., Li, J. H., Liu, T. Y., and Lin, T. C. (2000). Folk medicine Terminalia catappa and its major tannin component, punicalagin, are effective against bleomycin-induced genotoxicity in Chinese hamster ovary cells. Cancer Lett. 52, 115-122. doi: 10.1016/S0304-3835(99)00395-X

Chyau, C. C., Ko, P. T., and Mau, J. L. (2006). Antioxidant properties of aqueous extracts from Terminallia catappa leaves. LWT - Food Sci. Technol. 39, 1099-1108. doi: 10.1016/j.lwt.2005.07.016

Clinical and Laboratory Standards Institute (CLSI) (2008). Reference Method for Broth Dilution Antifungal Susceptibility Testing of Yeasts - Informational Supplement M27-A3. Wayne, MI: Clinical and Laboratory Standards Institute.

Costa, C. T. C., Bevilaqua, C. M. L., Morais, S. M., and Vieira, L. S. (2008). Taninos e sua utilização em pequenos ruminantes. Rev. Bras. Pl. Med. 10, 108-116.

de Paula, S. B., Morey, A. T., Santos, J. P., dos Santos, P. M. C., Gameiro, D. G., and Kerbauy, G., et al. (2015). Oral Candida colonization in HIV-infected patients in Londrina-PR, Brazil: antifungal susceptibility and virulence factors. J. Infect. Dev. Ctries. 9, 1350-1359. doi: 10.3855/jidc.6970

Fan, Y. M., Xu, L. Z., Gao, J., Wang, Y., Tang, X. H., Zhao, X. N., et al. (2004). Phytochemical and anti-inflammatory studies on Terminalia catappa. Fitoterapia 75, 253-260. doi: 10.1016/j.fitote.2003.11.007

Favalessa, O. C., Martins, M. A., and Hahn, R. C. (2010). Aspectos micológicos e suscetibilidade in vitro de leveduras do gênero Candida em pacientes HIVpositivos provenientes do Estado de Mato Grosso. Rev. Soc. Bras. Med. Trop. 43, 673-677. doi: 10.1590/S0037-86822010000600014
AT and CM participated in all manipulations, and they analyzed and interpreted the results; ACRB and ES participated in plant collection and phytochemical tests; EM, AP, and PC helped with bio-guided fractionation and participated in all antifungal tests. LT and AM were responsible by chemical analysis and identification of components of $\mathrm{FBuOH}$ and its sub-fractions; $\mathrm{AKDBF}$ has given substantial contributions to the conception or design of the work and revised the manuscript. EF revised the language of manuscript. All authors read and approved the final manuscript.

\section{ACKNOWLEDGMENTS}

The authors would like to thank the Foundation for Research and Scientific Development of Maranhão (FAPEMA; UNIVERSAL $\# 00740 / 13$ ) and the Coordination for the Improvement of Higher Level Personnel (Capes; Brazil; 3325/2013) for the financial support.

Fyhrquist, P., Mwasumbi, L., Haeggström, C. A., Vuorela, H., Hiltunen, R., and Vuorela, P. (2002). Ethnobotanical and antimicrobial investigation on some species of Terminalia and Combretum (Combretaceae) growing in Tanzania. J. Ethnopharmacol. 79, 169-177. doi: 10.1016/S0378-8741(01)0 0375-0

Gugnani, H. C., Becker, K., Fegeler, W., Basu, S., Chattopadhya, D., Baveja, U., et al. (2003). Oropharyngeal carriage of Candida species in HIV-infected patients in India. Mycoses 46, 299-306. doi: 10.1046/j.1439-0507.2003.00896.x

Hamza, O. J. M., Matee, M. I. N., Moshi, M. J., Simon, E. N. M., Mugusi, F., Mikx, F. H., et al. (2008). Species distribution and in vitro antifungal susceptibility of oral yeast isolates from Tanzanian HIV-infected patients with primary and recurrent oropharyngeal candidiasis. BMC Microbiol. 8:135. doi: 10.1186/1471-2180-8-135

Jagessar, R. C., and Alleyne, R. (2011). Antimicrobial potency of the aqueous extract of leaves of Terminalia catappa. Acad. Res. Int. 1, 362-371.

Junqueira, J. C., Vilela, S. F., Rossoni, R. D., Barbosa, J. O., Costa, A. C. Rasteiro, V. M., et al. (2012). Oral colonization by yeasts in HIV-positive patients in Brazil. Rev. Inst. Med. Trop. 54,17-24. doi: 10.1590/S0036-466520120001 00004

Kinoshita, S., Inoue, Y., Nakama, S., Ichiba, T., and Aniya, Y. (2007). Antioxidant and hepatoprotective actions of medicinal herb, Terminalia catappa L. from Okinawa Island and its tannin corilagin. Phytomedicine 14, 755-762. doi: 10.1016/j.phymed.2006.12.012

Kloucek, P., Polesny, Z., Svobodova, B., lkova, E., and Kokoska, L. (2005). Antibacterial screening of some Peruvian medicinal plants used in Calleria District. J. Ethnopharmacol. 99, 309-312. doi: 10.1016/j.jep.2005.01.062

Lim, S. H., Darah, I., and Jain, K. (2006). Antimicrobial activities of tannins extracted from Rhizophora apiculata barks. J. Trop. Forest Sci. 18, 59-65.

Lin, C. C., Hsu, Y. F., and Lin, T. C. (2001). Antioxidant and free radical scavenging effects of the tannins of Terminalia catappa. Anticancer Res. 21, 237-243.

Mandloi, S., Mishra, R., Varma, R., Varughese, B., and Tripathi, J. (2013). A study on phytochemical and antifungal activity of leaf extracts of Terminalia cattapa. Int. J. Pharm. Bio. Sci. 4, 1385-1393.

Matos, F. J. A. (1998). Introdução à Fitoquímica Experimental. Fortaleza: Edições EUFC.

McGinnis, M. (1980). Laboratory Handbook of Medical Mycology. New York, NY: Mycology Academic Press.

Moody, J. O., Adebiyi, O. A., and Adeniyi, B. A. (2004). Do Aloe vera and Ageratum conyzoides enhance the anti-microbial activity of traditional medicinal soft soaps (Osedudu)? J. Ethnopharmacol. 92, 57-60. doi: 10.1016/j.jep.2004. 01.018

Moura, M. D. G., Grossmann, S. M. C., Fonseca, L. M. S., Ramos-Jorge, M. L., and Mesquita, R. A. (2010). Risk factors for oral candidiasis 
in Brazilian HIV-infected adult patients. Braz. J. Oral Sci. 9, 470-474. doi: 10.20396/bjos.v9i4.8641742

Nair, R., and Chanda, S. (2008). Antimicrobial activity of Terminalia catappa, Manilkarazapota and Piper betel leaf extract. Indian J. Pharm. Sci. 70, 390-393. doi: 10.4103/0250-474X.43012

Naitik, P., Prakash, T., Kotresha, D., and Rao, N. R. (2012). Effect of Terminalia catappa on lipid profile in transplanted fibrosarcoma in rats. Indian J. Pharmacol. 44, 390-392. doi: 10.4103/0253-7613.96345

Okuda, T. (2005). Systematics and health effects of chemically distinct tannins in medicinal plants. Phytochemistry 66, 2012-2031. doi: 10.1016/j.phytochem.2005.04.023

Ozcelik, B., Kartal, M., and Orhan, I. (2011). Cytotoxicity, antiviral and antimicrobial activities of alkaloids flavonoids and phenolic acids. Pharm. Biol. 49, 396-402. doi: 10.3109/13880209.2010.519390

Packer, J., Naz, T., Elders, Y. C., Harrington, D., Jamie, J. F., and Vemulpad, S. R. (2015). Antimicrobial activity of customary medicinal plants of the Yaegl Aboriginal community of northern New South Wales, Australia: a preliminary study. BMC Res. Notes 8, 276. doi: 10.1186/s13104-0151258-x

Pandya, N. B., Tigari, P., Dupadahalli, K., Kamurthy, H., and Nadendla, R. R. (2013). Antitumor and antioxidant status of Terminalia catappa against Ehrlich ascites carcinoma in Swiss albino mice. Indian J. Pharmacol. 45, 464-469. doi: 10.4103/0253-7613.117754

Patil, S., Rao, R. S., Majumdar, B., and Anil, S. (2015). Clinical appearance of oral candida infection and therapeutic strategies. Front. Microbiol. 6:1391. doi: 10.3389/fmicb.2015.01391

Shinde, S. L., Junne, S. B., Wadje, S. S., and Baig, M. M. (2009). The diversity of antibacterial compounds of Terminalia species (Combretaceae). Pak. J. Biol. Sci. 12, 1483-1486. doi: 10.3923/pjbs.2009.1483.1486
Tan, G. T., Pezzuto, J. M., Kinghorn, A. D., and Hughes, S. H. (1991). Evaluation of natural products as inhibitors of human immunodeficiency virus type 1 (HIV1) reverse transcriptase. J. Nat. Prod. 54, 143-154. doi: 10.1021/np50073a012

Teodoro, G. R., Ellepola, K., Seneviratne, C. J., and Koga-Ito, C. Y. (2015). Potential use of phenolic acids as anti-candida agents: a review. Front. Microbiol. 6:1420. doi: 10.3389/fmicb.2015.01420

Triantafillidis, J. K., Triantafyllidi, A., Vagianos, C., and Papalois, A. (2016). Favorable results from the use of herbal and plant products in inflammatory bowel disease: evidence from experimental animal studies. Ann. Gastroenterol. 29, 268-281. doi: 10.20524/aog.2016.0059

Xiao, J., Capanoglu, E., Jassbi, A. R., and Miron, A. (2016). Advance on the flavonoid c-glycosides and health benefits. Crit. Rev. Food Sci. Nutr. 56, 29-45. doi: 10.1080/10408398.2015.1067595

Yeh, C. B., Yu, Y. L., Lin, C. W., Chiou, H. L., Hsieh, M. J., and Yang, S. F. (2014). Terminalia catappa attenuates urokinase-type plasminogen activator expression through Erk pathways in Hepatocellular carcinoma. BMC Complement Altern. Med. 14:141. doi: 10.1186/1472-6882-14-141

Conflict of Interest Statement: The authors declare that the research was conducted in the absence of any commercial or financial relationships that could be construed as a potential conflict of interest.

Copyright (C) 2017 Terças, Monteiro, Moffa, Santos, Sousa, Pinto, Costa, Borges, Torres, Barros Filho, Fernandes and Monteiro. This is an open-access article distributed under the terms of the Creative Commons Attribution License (CC BY). The use, distribution or reproduction in other forums is permitted, provided the original author(s) or licensor are credited and that the original publication in this journal is cited, in accordance with accepted academic practice. No use, distribution or reproduction is permitted which does not comply with these terms. 